\title{
Some Remarks about Shifting Cultivation in Netherlands New Guinea
}

\section{J. J. REYNDERS}

Soils Department, Mineralogical and Geological Institute, State University of Utrecht

\section{Summary}

The type of shifting cultivation and regeneration after clearing and agricultural exploitation of the forest on limestone soils in the Ajamaru district of Netherlands New Guinea is described. Analyses of soil samples show that:

1. The cultivation and regeneration period fit in the pattern of a sound agricultural system as proved by analytical data.

2. The organic matter content of the $\mathbf{A}_{1}$-horizon shows little variations during cultivation and regeneration.

3. The acidity of the topsoil is directly related to the exchangeable calcium.

\section{Introduction}

The agriculture of the Papuas, the native population in New Guinea, can be divided roughly in shifting cultivation in the hilly and mountainous areas and sago growing in the low swampy regions. The soils of the hilly and mountainous areas are mainly weathering products from limestones, marbles and sandstones. Generally spoken the soil has not been rejuvenated by volcanic ashes or deposition of erosion products from igneous formations. The areas occupied are mostly very steep and rugged so that erosion is a common feature and shallow soils are the result. The temperature is high and rainfall is abundant (average $3000-5000 \mathrm{~mm}$ per year).

The main food-crops are sweet potatoes (Ipomoea batatas) and taros (Colocasia esculenta). Under the prevailing circumstances with a few exceptions it is necessary to shift the cultivated area every 6 or 8 months.

During a field soil-survey in 1957 in the Ajamaru district (Birdshead of Dutch New Guinea) some observations were made and soil samples were taken from different stages of shifting-cultivation areas.

\section{General observations}

The vicinities of the native settlements Kofait and Fatase in the Ajamaru district (altitude about $200 \mathrm{~m}$ above sea-level) consist of pliocene limestone formations on which a medium deep to shallow yellowish brown to reddish yellow soil has developed. The average soil profile has the following morfology:

0-2 moisty, dark reddish brown (2.5YR2/4), organic rootmat;

2-10 moisty, rather loose, dark brown (10YR2/2), provided with organic matter, strongly rooted, silty loam ; irregulary waving transition into;

Received for publication 19th October, 1960. 
10-20 moisty, yellowish brown (7.5YR5/8) loam; merging into;

20-80 moisty, weakly compact, brown (5YR5/8) loam to loamy clay;

$80 \mathrm{~cm}$ dirty white limestone.

In this shifting-cultivation area mostly taros are planted. In consequence of the intensive shifting cultivation the vegetation consists predominantly of secondary forest. The roots of the trees lie on the soil surface. Only the smaller roots penetrate in the upper soil horizon, which is caused by the deficiency in nutritious substances in the subsoil. An equilibrium exsists between the decomposition of litter and the uptake of plantnutrients by the trees.

In GRAPH 1 showing the analyses of 5 soil profiles a good picture is given of the distribution of the most important exchangeable cations of the absorption complex through the whole profile.

GRAPH 1. The distribution of some exchangeable cations in the soil profile. (Samples taken in the middle of the profile horizon).

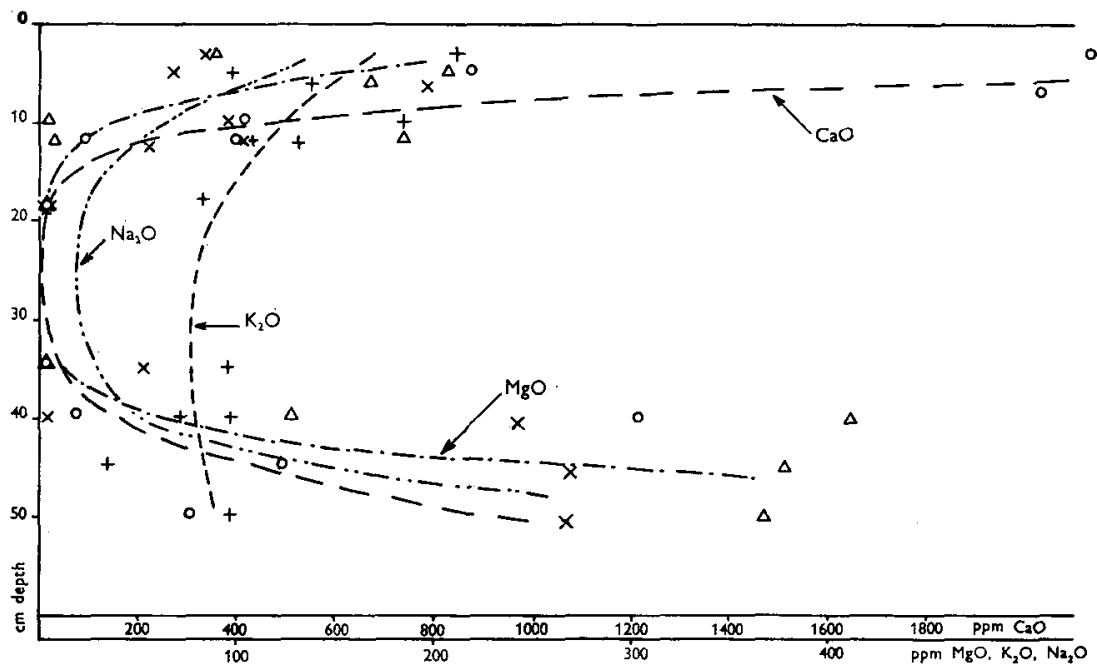

Note. Soil extraction in $3 \%$ acetic acid, 1:40. Analyses made by the Soils Laboratory of the Royal Tropical Institute, Amsterdam.

The area covered by a garden for one or more families varies from 0,2 to 5 acres. After gathering the undergrowth in heaps and cutting the higher trees of the forest the stems and branches are burned. The ash is spread over the new garden. Through this practice the Papua unknowingly gives a kind of potassium fertilization to his garden.

Around the garden a paling is built to protect the crop from pigs. Outside this fence a broad zone $(20$ to $30 \mathrm{~m})$ of trees is cut down to permit the sun to penetrate into the garden. As a result the toplayer of the soil becomes dryer and gets a fine crumbly structure.

By use of a planting stick the taro heads (leaf rosettes) are placed in the ash-covered soil. There is no other preparation of the soil. The toplayer consists of an organic rootmat $\left(A_{0}\right)$ of 2 to $5 \mathrm{~cm}$ lying on a humic soillayer $\left(A_{1}\right)$ of 5 to $15 \mathrm{~cm}$ deep. 
After two months, at the time that the leaves of the taros form a close cover over the soil, the organic rootmat is decomposed.

After 8 months the taros are harvested and the garden is abandoned. The secondary vegetation then coming into existence consists of grasses and ferns. After one year the whole garden is covered by a dense fern field in which only a few bushes are found. In the next two years a higher secondary vegetation, the so-called "blukar", develops poor in species. Field observations revealed that the rootsystems of these younger trees are normal (not superficial). The reason of this is that the soil is well aerated and perhaps some nutritious elements are washed out towards the deeper layers during the period of agricultural activity, the young trees, therefore, being tempted to grow their roots deeper. Unfortunately no samples were taken of the subsoil of the abandoned gardens.

After 15 to 20 years a new secondary forest has developed and no root penetration deeper than $20 \mathrm{~cm}$ is present; now the soil is in its original stage again.

In the Kofait and Fatase vicinities the rotation period also is 15 to 20 years. Further north, at the borders of the Ajamaru lakes the rotation period is shorter and as a result of that large fern fields, with a trees lacking, are widespread (over-cultivation). Samples of the topsoil, all of the same soil type, were taken to a depth of $15 \mathrm{~cm}$ in a limited area. In the TABLE the different soil stages are given. Each sample consists of a mixture of 4 sub-samples taken within a circle $10 \mathrm{~m}$ in diameter. No organic matter of the $A_{0}$ layer was added to the samples.

\section{Results}

Generally, in literature it is mentioned that in the shifting-cultivation system the crop derives great benefit of the decomposition of the organic matter. This is partly true. The $A_{0}$ horizon decays in two months and by the remineralization of the organic matter nutritious elements are set free but the organic matter in the $\mathbf{A}_{1}$ horizon does not change. The carbon content (after Walkley-Black) in the collected samples varies from 3 to $4 \%$ and there is no correlation between these percentages and the stage of cultivation or regeneration.

Soil acidity and the exchangeable elements calcium, magnesium, potassium and sodium are shown in the TABLE.

Comparing $\mathrm{pH}$ and $\mathrm{CaO}$-content in these humic topsoils it is clear that there is a direct relationship. In GRAPH 2 the broken line shows the general trend of this relation.

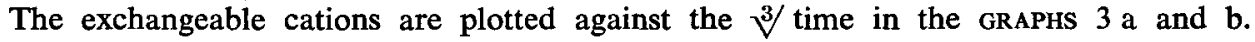
The various curved lines demonstrate the general trends (sample F 3 deviates so much from the trends of both graphs that it is not taken into account). Though more samples taken from the same stages or from more gardens would have given more accurate data the similarity of both series is such that it is possible to draw some conclusions.

During the cultivation period the ions will partly be assimilated by the crop, partly they will be washed down. The decrease in bivalent cations, especially of calcium is the greatest. The decrease of the monavalent cations is less but at the end of the cultivation period the exchangeable potassium nevertheless reaches a low value (extraction in $3 \%$ acetic acid, 1:40). Although it could be expected, it is interesting to note that for all cations the lowest point falls at the beginning of the regeneration. 
TABLE Stages and chemical analyses of topsoil samples of shifting-cultivation areas

\begin{tabular}{|c|c|c|c|c|c|c|}
\hline \multirow{2}{*}{$\begin{array}{l}\text { a. Kofai } \\
\text { Sample } \\
\text { Nr. }\end{array}$} & \multirow[b]{2}{*}{ Soil stage } & \multirow[b]{2}{*}{$\mathrm{pH}$} & \multicolumn{4}{|c|}{$3 \%$ acetic acid ppm } \\
\hline & & & $\mathrm{CaO}$ & $\mathrm{MgO}$ & $\mathrm{K}_{2} \mathrm{O}$ & $\mathrm{Na}_{2} \mathrm{O}$ \\
\hline $\begin{array}{ll}\mathbf{K} & 1 \\
\mathbf{K} & \mathbf{2} \\
\mathbf{K} & 3 \\
\mathbf{K} & 4\end{array}$ & $\begin{array}{l}1 \text { week after planting } \ldots \ldots \ldots \ldots \\
3 \text { months after planting } \ldots \ldots \ldots \\
6 \text { months after abandonment } \ldots \ldots \\
3 \text { years after abandonment } \ldots \ldots\end{array}$ & $\begin{array}{l}6,9 \\
5,8 \\
6,2 \\
6,4\end{array}$ & $\begin{array}{l}7200 \\
3800 \\
2100 \\
7000\end{array}$ & $\begin{array}{r}1100 \\
340 \\
280 \\
380\end{array}$ & $\begin{array}{l}410 \\
170 \\
110 \\
130\end{array}$ & $\begin{array}{r}220 \\
160 \\
80 \\
220\end{array}$ \\
\hline \multicolumn{7}{|c|}{ b. Fatase } \\
\hline $\begin{array}{ll}\text { F } & 1 \\
\text { F } & 2 \\
\text { F } & 3 \\
\text { F } & 4 \\
\text { F } & 5 \\
\text { F } & 6 \\
\text { F } & 7\end{array}$ & $\begin{array}{l}1 \text { day after planting } \ldots \ldots \ldots \ldots \\
1 \text { week after planting } \ldots \ldots \ldots \\
3 \text { months after planting } \ldots \ldots \\
\text { after } 8 \text { months at harvest } \ldots \ldots \\
8 \text { months after abandonment } \ldots \\
2 \text { years after abandonment } \ldots \ldots \\
10 \text { years after abandonment } \ldots \ldots\end{array}$ & $\begin{array}{l}6,5 \\
5,9 \\
7,0 \\
5,8 \\
5,7 \\
5,6 \\
6,0\end{array}$ & $\begin{array}{r}4100 \\
2700 \\
4600 \\
250 \\
\text { tr } \\
30 \\
1900\end{array}$ & $\begin{array}{r}600 \\
370 \\
830 \\
30 \\
\text { tr } \\
\text { tr } \\
450\end{array}$ & $\begin{array}{l}250 \\
245 \\
180 \\
180 \\
105 \\
120 \\
180\end{array}$ & $\begin{array}{r}230 \\
80 \\
270 \\
40 \\
65 \\
55 \\
510\end{array}$ \\
\hline
\end{tabular}

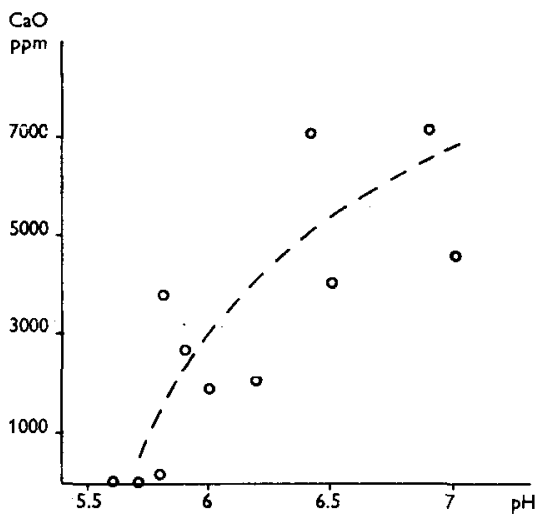

GRAPH 2. Relation between exchangeable calcium and $\mathrm{pH}$ of the topsoil $\left(\mathrm{A}_{1}\right)$.

In GRAPH 3 it can be seen that the Fatase samples, by abandonment, practically have no magnesium and calcium content at all.

\section{Conclusion}

It is clear that the Papua puts the most economic cultivation system into practice and that it is impossible to grow a secondary crop in the same garden in this region. After a period of 15 to 20 years the topsoil will be in the initial stage of fertility again and then a new garden can be made. The shifting-cultivation system is adapted to the fertility level of the soil and to the time it needs for regeneration. 
SOME REMARKS ABOUT SHIFTING CULTIVATION IN NETH. NEW GUINEA
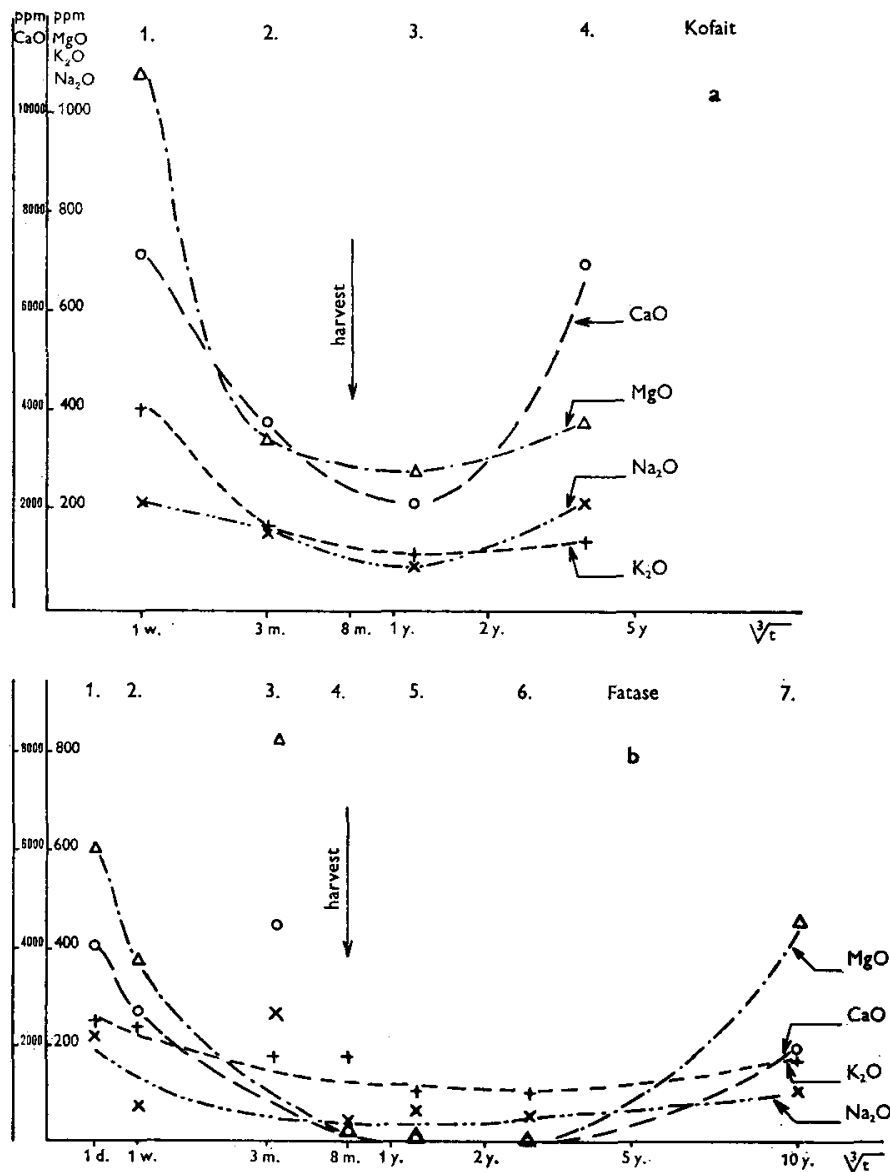

GRAPH 3. Relationship between some exchangeable cations during cultivation and regeneration near Kofait and Fatase.

(Topsoil sample after removal of organic rootmat). 